\title{
COVID-19 vaccination and public health measures
}

\author{
Gentle Sunder Shrestha*, Sabin Bhandari \\ Department of Anaesthesiology, Tribhuvan University Teaching Hospital, Maharajgunj, Kathmandu, Nepal
}

\section{LETTER TO EDITOR}

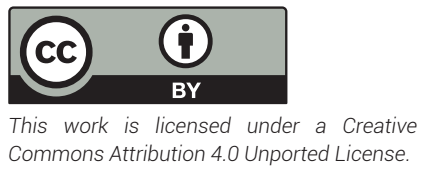

As the Covid-19 pandemic has dragged on, "pandemic fatigue" among both health care workers and general public, has attenuated the magnitude of fear initially observed. Preventive measures like social distancing, wearing masks, washing hands and staying at home have waned and the behaviors like increased contact with people, eating outdoor and visiting public places without masks seems increasing. With the global roll out of Covid-19 vaccines, and the perception of it being a panacea to the current pandemic, the "Peltzman Effect" probably exists, wherein, individuals are responding to the safety measures like vaccination with a compensatory increase in risky behavior.?

The apparent lack of, or presence of only mild symptoms in most patients, have also lead to decreased compliance to public health measures. However, 59\% of all transmission is from asymptomatic individuals, prompting us to rethink our current strategy of identification and isolation of persons with symptomatic COVID-19, which though helpful, is only partially effective in controlling the spread. ${ }^{2}$

Apart from human factors, the rapid emergence of variants like B.1.1.7 (the UK or Kent variant), B.1.351 (the South Africa variant) and P.1 (the Brazilian variant) have complicated the efforts of containing the pandemic. These variants are associated with increased transmissibility, disease severity, reinfection rates, and decreased vaccine effectiveness. ${ }^{3}$ Hacisuleyman et al recently published two cases of vaccine breakthrough infections in patients who had received the apparently highly effective BNT162b2 (Pfizer-BioNTech) and mRNA-1273 (Moderna) vaccines, raising the probability of variants evading vaccine-induced immunity and causing asymptomatic infection (and thereby promoting viral spread) or illness. ${ }^{4}$

The importance of stringent public health measures has been highlighted by Chu et al by demonstrating reduced viral transmission with physical distancing of one meter or more, application of face masks, specially N95 or similar respirators, and eye protection. ${ }^{5}$ Complacency in implementing these measures has resulted in devastating loss of lives across the globe. Similarly, over reliance on vaccination which is progressing at snail's pace, with uncertain efficacy against all the emerging variants, and without tests to know its effectiveness, may confer a false sense of security. There is thus a mandatory need for health care workers and general public, either vaccinated or not, to comply with the standard public health measures till the globe sees a true panacea from this pandemic, that may be a far cry, at least for now. Overindulgence with risk compensating behaviors can obviously incur harm.

\section{Conflicts of Interest: None}

\section{Acknowledgements: None}

\section{Funding source: None}

\section{REFERENCES}

1. Trogen B, Caplan A. Risk Compensation and COVID-19 Vaccines. Ann Intern Med. 2021 Mar 2. doi:10.7326/M20-8251. [Epub ahead of print].

2. Johansson MA, Quandelacy TM, Kada S, et al. SARSCoV-2 Transmission From People Without COVID-19 Symptoms. JAMA Netw Open. 2021; 4(1):e2035057. doi:10.1001/jamanetworkopen.2020.35057

3. Abdool Karim SS, de Oliveira T. New SARS-CoV-2 Variants Clinical, Public Health, and Vaccine Implications. N Engl J Med 2021 Mar 24:NEJMc2100362. doi: 10.1056/NEJMc2100362. [Epub ahead of print].

4. Hacisuleyman E, Hale C, Saito $Y$, et al. Vaccine Breakthrough Infections with SARS-CoV-2 Variants. N Engl J Med. 2021 Apr 21. doi:10.1056/NEJMoa2105000. [Epub ahead of print].

5. Chu DK, AkI EA, Duda S, et al. COVID-19 Systematic Urgent Review Group Effort (SURGE) study authors. Physical distancing, face masks, and eye protection to prevent personto-person transmission of SARS-CoV-2 and COVID-19: a systematic review and meta-analysis. Lancet 2020 Jun 27; 395(10242):1973-1987. doi: 10.1016/S0140-6736(20)311429.

*Corresponding Author | Dr. Gentle Sunder Shrestha, Associate Professor, Department of Anaesthesiology, Tribhuvan University Teaching Hospital, Maharajgunj | Email: gentlesunder@hotmail.com | Phone: +977-9841248584 